\title{
Quantitative image of fluorescence of ceramic and resin-cement veneers
}

\author{
Francisca Daniele Jardilino \\ SILAMI(a) \\ Sebastião PRATAVIEIRA ${ }^{(b)}$ \\ Marcelo Saito NOGUEIRA ${ }^{(b)}$ \\ Allyson Anne BARRETT(c) iD \\ Mário Alexandre Coelho \\ SINHORETI(d) \\ Saulo GERALDELI(c) iD \\ Fernanda de Carvalho Panzeri \\ PIRES-DE-SOUZA ${ }^{(e)}$ \\ (a) Universidde Federal de Minas Gerais - \\ UFMG, School of Dentistry, Department of \\ Clinical, Pathology and Dental Surgery, Belo \\ Horizonte, MG, Brazil. \\ (b) Universidade de São Paulo - USP, São Carlos \\ Institute of Physics, São Carlos, SP, Brazil. \\ (c) University of Florida, College of Dentistry, \\ Center for Dental Biomaterials, Gainesville, \\ FL, United States \\ (d) Universidade Estadual de Campinas \\ - Unicamp, Piracicaba Dental School, \\ Department of Restorative Dentistry, \\ Piracicaba, SP, Brazil. \\ (e) Universidade de São Paulo - USP, Ribeirão \\ Preto School of Dentistry, Department \\ of Dental Materials and Prosthodontics, \\ Ribeirão Preto, SP, Brazil.
}

Declaration of Interests: The authors certify that they have no commercial or associative interest that represents a conflict of interest in connection with the manuscript.

Corresponding Author:

Fernanda de Carvalho Panzeri Pires-de-Souza E-mail address: ferpanzeri@usp.br

ht1ps://doi.org/10.1590/1807-3107bor-2019.vol33.0088

Submitted: March 11, 2019

Accepted for publication: August 2, 2019

Last revision: August 13, 2019
Abstract: The main of the study was quantify the effect of two ceramics with two underlying resin cements on apparent fluorescence levels. Buccal surfaces of two bovine incisors were ground flat producing one enamel and one dentin substrate. The veneers were fabricated (0.5 and $1.0 \mathrm{~mm}$ thickness) using two ceramics (IPSe.max Press and IPSe.max Zirpress, Ivoclar Vivadent). Veneers were cemented using either light-cured (Variolink II, Ivoclar Vivadent) or self-adhesive dual (Rely X U200, 3M ESPE) cement. The layered Control group materials had no cement application. Semi-quantitative fluorescence image analysis (Matlabs software, Matworks) involved processing the images as captured under each daylight (DL, Gretagmacbeth) and ultraviolet illuminants (UVA, Sylvania) within a neutral-gray lightbox (Macbeth Spectral Light). Statistical analysis of the quantitative fluorescence values was performed using two-way ANOVA and Tukey's test $(p<0.05)$. The e.max Zirpress on the dentin substrate produced greater fluorescence $(p<0.05)$ when subjected to UV illumination and more fluorescence $(p<0.05)$ than e.max Press in both cement groups. Light-cured cement produced higher $(p<0.05)$ fluorescence than the dual-cement with e.max Press on enamel under UV illumination. The fluorescence for e.max Press on the dentin substrate was greater $(p<0.05)$ than for e.max Zirpress using dual self-adhesive cement subjected to daylight illumination. Thus, it is possible to conclude that the combination of ceramic and cement produce definite, significant effects on the apparent fluorescence, vital quality for restorative dentistry.

Keywords: Dental Veneers; Resin Cements; Fluorescence.

\section{Introduction}

Esthetic restorations should always portray the natural characteristics of the tooth to optimize a final esthetic appearance. ${ }^{1}$ Therefore it follows that composites and ceramics should mimic the tooth's optical properties, such as fluorescence, opacity, opalescence, and translucency. ${ }^{2}$ Fluorescence is the light a material re-emits after an illuminant shines upon the material. It occurs when a substance absorbs and re-emits the light at a longer wavelength. ${ }^{3}$ In natural teeth, fluorescence is stimulated by ultraviolet (UV) radiation, which influences the tooth's brightness ${ }^{4}$ producing a lively appearance. This optical property depends on both the duration of time the tooth was exposed to a UV illuminant and subsequently, on 
the tooth's wavelength re-emission. Therefore, the more UV light absorbed by the tooth, the greater the fluorescence re-emission. ${ }^{5}$ The fluorescence of natural teeth exhibits a bluish-white color and is best described as a phenomenon of immediate and concomitant photoluminescence. However, since the tooth's fluorescence depends on the length of exposure to the UV source, the excitation diminishes after the stimulating light source is removed. ${ }^{5}$

Dental studies have reported differences both for the intensity and wavelength of fluorescence emitted from the teeth and resin restorations when illuminated by specific lights ${ }^{6,7}$ such as black light in nightclubs. The materials may appear as black-spaces ${ }^{2}$ with no apparent fluorescence, effectively making the restoration invisible, suggesting a failure in dental treatment.

The tissues of enamel and dentin produce varying degrees of fluorescence, ${ }^{2,8}$ however, dentin is the main component responsible for the fluorescence in natural dentition. The dentin is composed of collagen and high amounts of amino acids like tryptophan, which emanates fluorescence, making this substrate three times more fluorescent than the enamel. ${ }^{910}$ In contrast, the enamel's fluorescence is composed of only $2 \%$ organic components. However, a restoration's final aesthetic appearance also depends on the interaction between the tooth, the resin cement, and porcelain veneers. The interactive effects determine if these restorative materials mimic the tooth's structure, ${ }^{11}$ minimizing differences between the fluorescence of enamel and dentin. On the other hand, a new recent study used sunlight to determine experimentally the significance to tooth fluorescence in perceived tooth color and concluded that UV-induced fluorescence of natural teeth no influence tooth color under normal daylight conditions disagreeing with actual literature and encouraging news research. ${ }^{12}$

Fluorescent additives such as europium, ytterbium, and other rare-earth elements, exhibiting visible fluorescence, ${ }^{13}$ are included in compositions for restorative resin cements and ceramics that are designed to match the fluorescence of natural esthetic tooth structure. ${ }^{14}$ The amounts, types, and ratios of these components vary among products and manufacturers. ${ }^{8,15}$ As a result, different materials present different fluorescent effects under the same condition. ${ }^{8}$

Laminate veneers are prosthetic restorations that also embellish one's smile. ${ }^{11}$ The success of this restorative treatment depends upon multiple variables including tooth substructure, ${ }^{16}$ thicknesses, ${ }^{17}$ ceramic, ${ }^{18}$ and, the resin-cement type..$^{19}$ Dental ceramic is the most widely used material for veneers given color stability, chemical inertia, translucence and its capacity to mimic natural dentition. ${ }^{11,18}$ Currently, there are many types of dental ceramics marketed with varying specifications and technical features. However, pressed ceramic has been widely used for veneering due to its predictability and reliability. ${ }^{18}$

Heat pressed lithium disilicate glass ceramic (e.maxPress), and fluorapatite glass ceramic (e.max Zirpress) are available in ingots of different translucency and opacity. ${ }^{20}$ Lithium disilicate glass ceramic has excellent mechanical properties compared with conventional porcelains ${ }^{21}$, and it is usually used to dental prosthetic rehabilitation due to excellent optical properties. ${ }^{20}$ Fluorapatite glass ceramic is veneering porcelain, and it can be used to make restorations monolithic or bilayer with zirconia core..$^{22}$

Ceramic veneers are not mechanically retentive; therefore, they rely on resin cements for adhesion and long-lasting intra-oral survival. ${ }^{23}$ Light-curing resin cement is generally preferred for cementation of laminate veneers, but the self-adhesive resin cements were introduced, eliminating the need for tooth surface pretreatment, reducing technique sensitivity, and simplify the luting procedures. ${ }^{24}$ Depending on the thickness of the restoration, the resin cement may either increase or decrease the fluorescence of the ceramic veneer restorations. ${ }^{25}$

The aim of this study was to analyze the effect of different resin cements and ceramics on veneer fluorescence. The null hypothesis for this research was: There is no difference in the fluorescence of restorations regardless of the type of resin cements and ceramic materials studied.

\section{Methodology}

The materials used in study are in Table 1 and a flowchart (Figure 1) summarize the used methodology. 


\section{Sample preparation}

Two different ceramics (Table 1) were used to fabricate twenty samples $(6 \mathrm{~mm}$ diameter $)$ in two thicknesses $(0.5 \mathrm{~mm}$ and $1 \mathrm{~mm})$. Using the lost wax investment method, melted wax (Rainbow, Porto Ferreira, Brazil) was placed in a Teflon mold. After cooling, wax patterns were sprued onto silicon rings (IPS Silicon Ring, Ivoclar/Vivadent AG Schaan, Liechtenstein) following the manufacturer's guidelines. The investment material (IPS PressVest, Ivoclar/Vivadent AG Schaan, Liechtenstein) was measured, mixed with the designated liquids, and poured into the silicon rings.

After the material set, the silicon rings were removed, and the investment cylinder processed (3000-3P EDG, EDG Equipamentos e Controles, Sao Carlos, Brazil) at $850^{\circ} \mathrm{C}$ to burn-out the wax. Ceramic was invested and pressed followed in the furnace (Programat EP 5000 Ivoclar/Vivadent AG Schaan, Liechtenstein). The standardized pressing process for each type of ceramic was followed according to the manufacturer's specifications. ${ }^{26}$

After cooling, the specimens were separated, finished with microsphere abrasion (Renfert, Hilzingen, Germany), and polished using abrasive stones, diamond burs and specific rubber discs (EVE Ernst VetterGmbH, Pforzheim, Germany). The samples were cleaned ultrasonically (Cristófoli, Cristófoli Equipamentos de Biossgurança LTDA., Campo Mourão, Brazil) using Invex Liquid (10 m)
(Ivoclar/Vivadent AG Schaan, Liechtenstein), rinsed under running water, dried with compressed air, and blasted with spherical aluminum oxide particles at 1-2 bar pressure.

Each sample was wet polished (Polipan-U, Panambra, São Paulo, Brazil) with abrasive papers (Norton 600, 1000 and 1200 grits) and the final thickness was measured (Digital caliper, Digimess Instruments Precision LTDA, São Paulo, Brazil). The ceramic specimens were cleaned (ethanol 90\%) ultrasonically $(4 \mathrm{~m})$. The prepared discs were then glazed $\left(403^{\circ} \mathrm{C} / 6\right.$ minutes and $770{ }^{\circ} \mathrm{C} / 1.5$ minutes).

\section{Substrate preparation}

Two freshly extracted bovine incisors were sectioned below the cement-enamel junction $(1 \mathrm{~mm})$, then embedded in acrylic resin, exposing the buccal surface. The incisors were flattened (Polipan-U, Panambra, São Paulo, Brazil) by wet grinding with abrasive grits 320 and 1200 (Norton, São Paulo, Brazil) producing an enamel and dentin surfaced substrate.

\section{Sample cementation}

Neither the enamel nor the dentin substrates were acidly etched for the cementation simulation. The surfaces of e.max Zirpress were air-abraded with $90 \mu \mathrm{m}$ spherical aluminum oxide particles (Bioart, São Carlos, Brazil) at 1 bar (5 s), rinsed and treated (60 s) with a silane coupling agent (Monobond S; Ivoclar/Vivadent, Schaan, Liechtenstein). The e.max

Table 1. Materials used in this study.

\begin{tabular}{|c|c|c|}
\hline Brand name & Composition & Manufacter \\
\hline $\begin{array}{l}\text { IPS e.max Press } \\
\text { Al HT }\end{array}$ & $\begin{array}{c}\text { Main ingredient: } \mathrm{SiO}_{2} \\
\text { Other ingredients: } \mathrm{Li}_{2} \mathrm{O}, \mathrm{K}{ }_{2} \mathrm{O}, \mathrm{MgO}, \mathrm{ZnO}, \mathrm{Al}_{2} \mathrm{O}_{3}, \mathrm{P}_{2} \mathrm{O}_{5} \text {. }\end{array}$ & $\begin{array}{l}\text { Ivoclar/Vivadent AG, Schaan, } \\
\text { Liechtenstein }\end{array}$ \\
\hline $\begin{array}{l}\text { IPS e.max Zirpress } \\
\text { Shade Al HT }\end{array}$ & $\begin{array}{c}\text { Main ingredient: } \mathrm{SiO}_{2} \\
\text { Other ingredients: } \mathrm{Li}_{2} \mathrm{O}, \mathrm{Na}_{2} \mathrm{O}, \mathrm{K} \mathrm{O}_{2}, \mathrm{MgO}, \mathrm{Al}_{2} \mathrm{O}_{3}, \mathrm{CaO}, \mathrm{ZrO}_{2}, \mathrm{P}_{2} \mathrm{O}_{5} \mathrm{e}\end{array}$ & $\begin{array}{l}\text { Ivoclar/Vivadent AG, Schaan, } \\
\text { Liechtenstein }\end{array}$ \\
\hline RelyX U200 & $\begin{array}{l}\text { Base paste: fiberglass, phosphoric acid methacrylate esters, TEGDMA, } \\
\text { silano treated sílica and sodium persulfate. } \\
\text { Catalyst paste: fiberglass, substitute dimethacrylate, silane treated sílica, } \\
\text { P-tolvenesufonate sodium and calcium hydroxide. }\end{array}$ & 3M ESPE, Seefeld, Germany \\
\hline $\begin{array}{l}\text { Variolink II } \\
\text { Translucent }\end{array}$ & $\begin{array}{c}\text { Monomers: Bis-GMA, UDMA, EDMA } \\
\text { Filler particles: silica, barium glass, ytterbium trifluoride. } \\
\text { Other components: catalysts, stabilizers and pigments }\end{array}$ & $\begin{array}{c}\text { Ivoclar/Vivadent AG, Schaan, } \\
\text { Liechtenstein }\end{array}$ \\
\hline Glaze IPS e.max Ceram Paste & Oxides, glycerine, butanediol, polyvinyl pyrrolidine & $\begin{array}{l}\text { Ivoclar/Vivadent AG, Schaan, } \\
\text { Liechtenstein }\end{array}$ \\
\hline
\end{tabular}

Bis-GMA, Bisphenol-A glycidyldimethacrylate; UDMA-Urethanedimethacrylate; TEGDMA, Triethyleneglycol dimethacrylate; EDMA. 


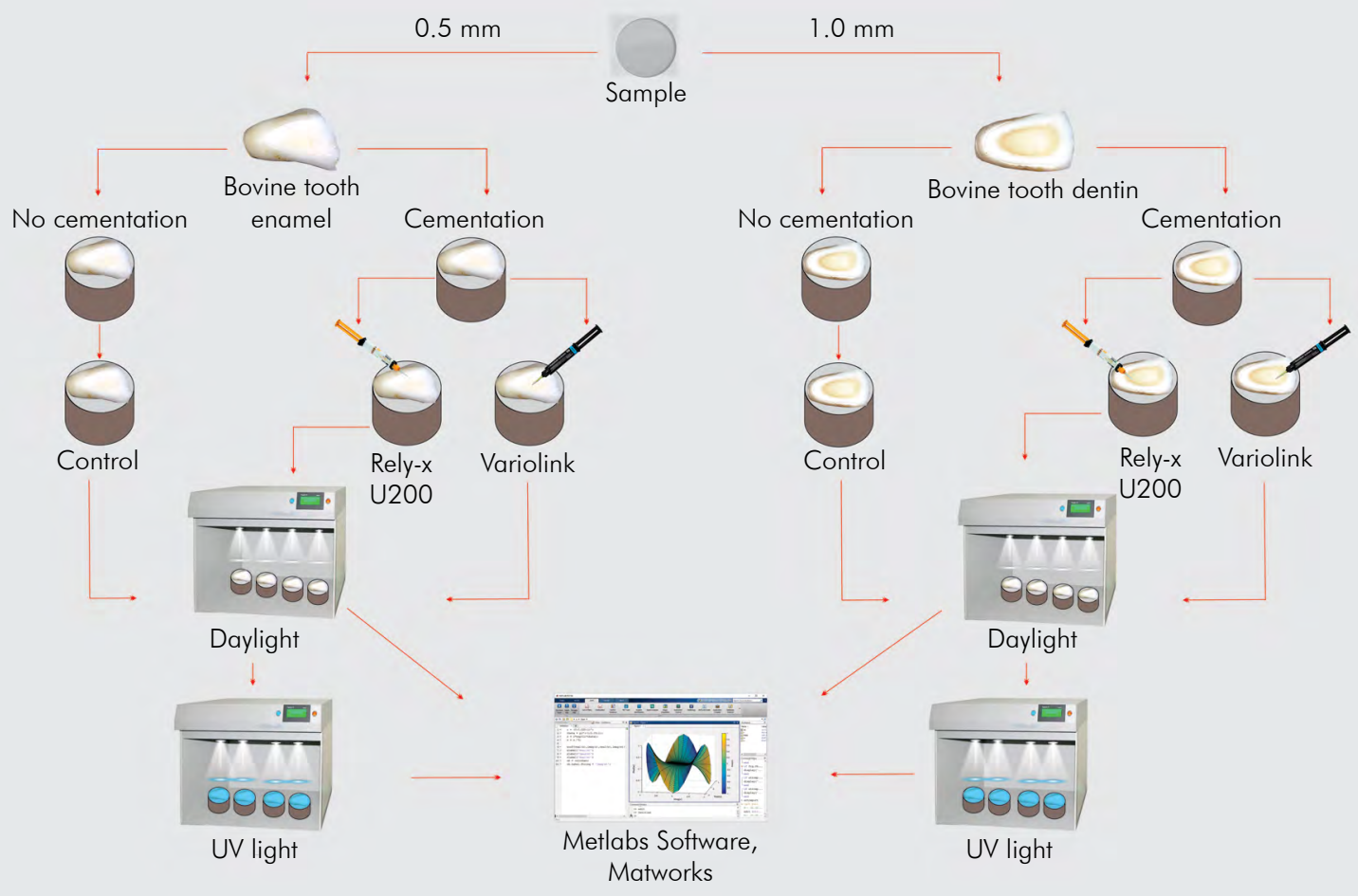

Figure 1. Flowchart that shows the protocol used in the study

Press ceramic samples were conditioned (20 s) with hydrofluoric acid (10\%) (Dentsply, Petrópolis, RJ, Brazil), rinsed with water spray, air-dried, and silanized (60 s) (Monobond S; Ivoclar/Vivadent, Schaan, Liechtenstein). Both processes followed the manufacturer's instructions.

Before the application of the resin cement, the dental substrates were covered with a protective plastic film to ensure that the one each enamel and the dentin substrates remained unaffected by any resin cement or layering process. After protection, the dental substrates were fixed with soft wax on the horizontal plane. The $0.5 \mathrm{~mm}$ laminate veneers were placed on enamel substrate while the $1.0 \mathrm{~mm}$ was tested on dentin substrate. The same tooth, flattened in the enamel or dentin, was used for the fluorescence image capture, with both cements, reducing any possible variation of the dentition component in fluorescence analysis.

Using a parallelometer, the resin cements (Variolink II, Ivoclar/Vivadent AG Schaan, Liechtenstein or Rely-X U200, 3M ESPE, Seefeld, Germany) were placed on the center of each ceramic veneer, on the top of the film-protected enamel or dentin substrate control. To standardize the pressure for cement thickness, $380 \mathrm{~g}$ of weight was applied (10 s) on the device. Excess cement was gently removed, and the material was light-cured (40 s) using an LED light-curing unit (irradiance 1,000 mW/cm2; Valo, Ultradent, Salt Lake, USA). Each cement sample was removed from the substrate and stored in dark vessels at $37^{\circ} \mathrm{C}$ for $24 \mathrm{~h}$. For each substrate (enamel or dentin), the samples of ceramics, respectively with $0.5 \mathrm{~mm}$ and $1 \mathrm{~mm}$, were randomly separated by resin cement type $(n=5)$.

\section{Image capture of samples}

Two-dimensional digital images of each sample combination (ceramic + resin cement) were captured within a standardized lightbox (Macbeth Spectra Light, New York, USA) with a standardized neutral-gray (Munsell N-7) surround. The illuminants included: 1) daylight illuminate, wavelength range $\sim 380$ to 780 nm (Gretagmacbeth, 6500, F20T12/65, 20W, Grand Rapids, USA), and 2) ultraviolet illuminate, wavelength 
range $\sim 340$ to $400 \mathrm{~nm}$ (UV-A Sylvania, Blacklight Blue, F30T8/BLB, 30W, Wilmington, USA). An ensured formation of a perpendicular angle between the sample and the camera (Cannon, Rebel T3i, Tokyo, Japão) was maintained. Images were captured with the ISO 400 at a standardized distance of $15 \mathrm{~cm}$ between the specimen and the camera. The exposure time was set at $4 \mathrm{~s}$ under the daylight illuminant and $0.8 \mathrm{~s}$ under the UV illuminant. During intervals between images captures, the bovine dental substrates were stored in distilled water $\left(37^{\circ} \mathrm{C}\right)$. The sequential image captures had a ceramic sample placed on the designated dental substrate with no resin cement (control), while the subsequent image capture placed the resin cement between the dental substrate and the ceramic veneer. All the materials followed this sequential order.

\section{Fluorescence analysis}

The semi-quantitative fluorescence image analysis compared the two-dimensional digital images of the veneers captured under each of the two illuminants. The mathematical and digital software (Matlabs software, Matworks, Natick, USA) imaging tools were employed to quantify the fluorescent contrast effect among the restorative material, the resin cement, and the dental substrate. ${ }^{27}$

The image analysis methodology required the conversion of all sample images to grayscale levels standardizing image comparison for quantification. Thus, the intensity of fluorescence detected for all groups was calculated by grayscale level using the Matlab software (Matworks, Mathematical Computing Software, Natick, USA). Image analysis comparison factored the emission's grayscale intensity rather than color analysis.

The grayscale levels were transformed into absolute numbers using a Matlab function ("rgb2gray"). The contrast between the restoration and the substrate was calculated by dividing the contrast of the restoration by the contrast of the substrate. Using a MatLab algorithm that executes the following functions: a) images are converted to grayscale; b) the image intensity of the resin cement is measured (region of interest - ROI 1); c) the image intensity around the resin (i.e., the bovine substrate) is measured (ROI 2); d) a ratio of the intensity of the resin to the surrounding intensity is calculated (ROI 1/ ROI 2). If this ratio was greater than 1 , the restoration was more visible (i.e., fluorescent) than the substrate. If the ratio was less than 1, the substrate was more visible and presented more contrast than the restoration. If the ratio was equal to 1 , there was no difference between the restoration and the background intensity levels, and there would be no distinction between them.

\section{Statistical analysis}

Based on the means and standard deviations comparisons between the groups, and considering two-sided 95\% confidence interval (two-sided), the power of the sample size was considered as $100 \%$ (http://openepi.com). The normal distribution of data was analyzed using the Kolmogorov-Smirnov test. Statistical differences of the ceramic veneering fluorescence intensity values were analyzed using Two-way ANOVA (variation factors: ceramic type and resin cement) with Bonferroni correction and Tukey's post-hoc test, with a $95 \%$ significance level.

\section{Results}

The mean differences and statistical significance for fluorescent intensity levels using laminate veneers with $0.5 \mathrm{~mm}$ and $1.0 \mathrm{~mm}$ thicknesses are presented in Tables 2 and 3, respectively. The tables display the statistical relevance for the two ceramics under each illumination, with each cement, and the control (no cement) group also. Figures 2 and 3 present the images captured on daylight and UV-light, enamel and dentin, respectively. It is possible to compare the differences on the fluorescence of the teeth and the veneers fixed with the tested cements.

There was no statistically significant difference $(p>0.05)$ in fluorescence intensity levels for either the ceramics, resin cements, or the controls under the daylight illuminant (Table 2). Under UV illumination $0.5 \mathrm{~mm}$ e.max Press veneers presented greater fluorescence $(\mathrm{p}<0.05)$ with Variolink II when compared with RelyX U200 and Control groups. Samples of e.max ZirPress showed a greater fluorescence $(p<0.05)$ than e.max Press for all tested groups. There was no difference $(p>0.05)$ on the fluorescence of e.max Zirpress when the resin cements and the control group $(p>0.05)$ were compared. 
Table 2. Enamel fluorescence intensities for $0.5 \mathrm{~mm}$ laminate veneers considering resin cements, type of ceramic and light source (daylight or UV).

\begin{tabular}{lcccc}
\hline \multirow{2}{*}{ Variable } & \multicolumn{2}{c}{ Daylight } & \multicolumn{2}{c}{ UV } \\
\cline { 2 - 5 } & e.max Press & e.max Zirpress & e.max Press & e.max Zirpress \\
\hline RelyX U200 & $0.99 \pm 0.02 \mathrm{aA}$ & $0.96 \pm 0.00 \mathrm{aA}$ & $0.84 \pm 0.01 \mathrm{aA}$ & $0.97 \pm 0.01 \mathrm{bA}$ \\
Variolink II & $0.98 \pm 0.01 \mathrm{aA}$ & $0.96 \pm 0.00 \mathrm{aA}$ & $0.95 \pm 0.05 \mathrm{aB}$ & $1.02 \pm 0.01 \mathrm{bA}$ \\
Control (no resin cement) & $0.95 \pm 0.03 \mathrm{aA}$ & $0.95 \pm 0.01 \mathrm{aA}$ & $0.85 \pm 0.01 \mathrm{aA}$ & $0.98 \pm 0.01 \mathrm{bA}$ \\
\hline
\end{tabular}

Different letters, capital in column and lower case in row, for each reading light, indicate statistically significant difference (2-way ANOVA, Bonferroni, $p<0.05$ ).

Table 3. Dentin fluorescence intensities for $1 \mathrm{~mm}$ laminate veneers considering resin cements, types of ceramic and light source (daylight or UV).

\begin{tabular}{lcccc}
\hline \multirow{2}{*}{ Variable } & \multicolumn{2}{c}{ Daylight } & UV \\
\cline { 2 - 5 } & e.max Press & e.max Zirpress & e.max Press & e.max Zirpress \\
\hline RelyX U200 & $1.01 \pm 0.01 \mathrm{aA}$ & $0.95 \pm 0.00 \mathrm{bA}$ & $0.74 \pm 0.00 \mathrm{aA}$ & $0.85 \pm 0.00 \mathrm{bA}$ \\
Variolink II & $0.99 \pm 0.03 \mathrm{aA}$ & $1.00 \pm 0.02 \mathrm{aA}$ & $0.78 \pm 0.02 \mathrm{aA}$ & $0.86 \pm 0.03 \mathrm{bA}$ \\
Control (no resin cement) & $1.03 \pm 0.02 \mathrm{aA}$ & $0.97 \pm 0.01 \mathrm{bA}$ & $0.77 \pm 0.03 \mathrm{aA}$ & $0.86 \pm 0.00 \mathrm{bA}$ \\
\hline
\end{tabular}

Different letters, capital in column, and lower case in rows, for it reading light, indicate statistically significant results (2-way ANOVA, Bonferroni, $p<0.05)$.

On the dentin substrate (Table 3), e.max Press veneers under daylight exhibited greater fluorescence $(\mathrm{p}<0.05)$ than e.max Zirpress control group and when cemented with Rely X U200. However, there was no difference $(p>0.05)$ on fluorescence between ceramics when cemented with Variolink II. Under UV, e.max Zirpress ceramic produced greater fluorescence than the e.max Press $(p<0.05)$ for both resin cements and the control group. There were no differences $(p>0.05)$ comparing the resin cements and control group for both types of ceramic and illuminant sources.

The means for the fluorescence intensity levels of ceramic with no resin cement under daylight and UV illumination are presented in Table 4 . The fluorescence of laminate veneers without resin cement was greater $(\mathrm{p}<0.05)$ under daylight than under UV illumination, for both the enamel and dentin substrates, considering both ceramics.

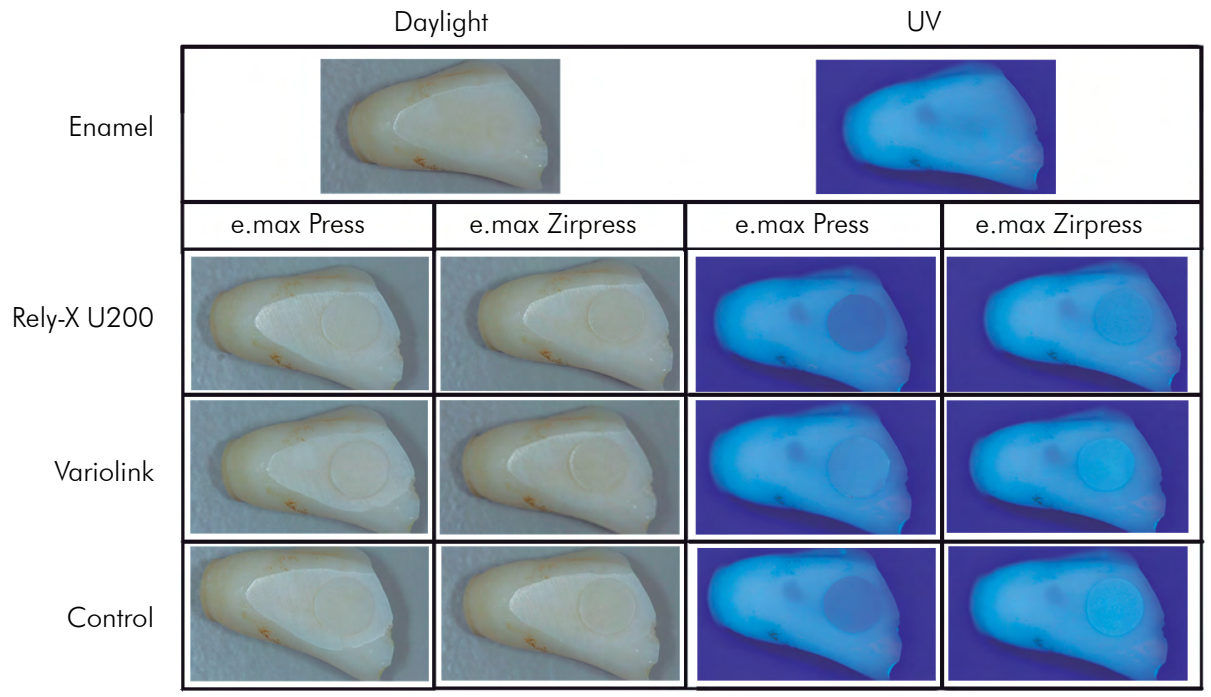

Figure 2. Images of the teeth, flattened on enamel, and the $0.5 \mathrm{~mm}$ veneers captured under daylight and UV-light. 


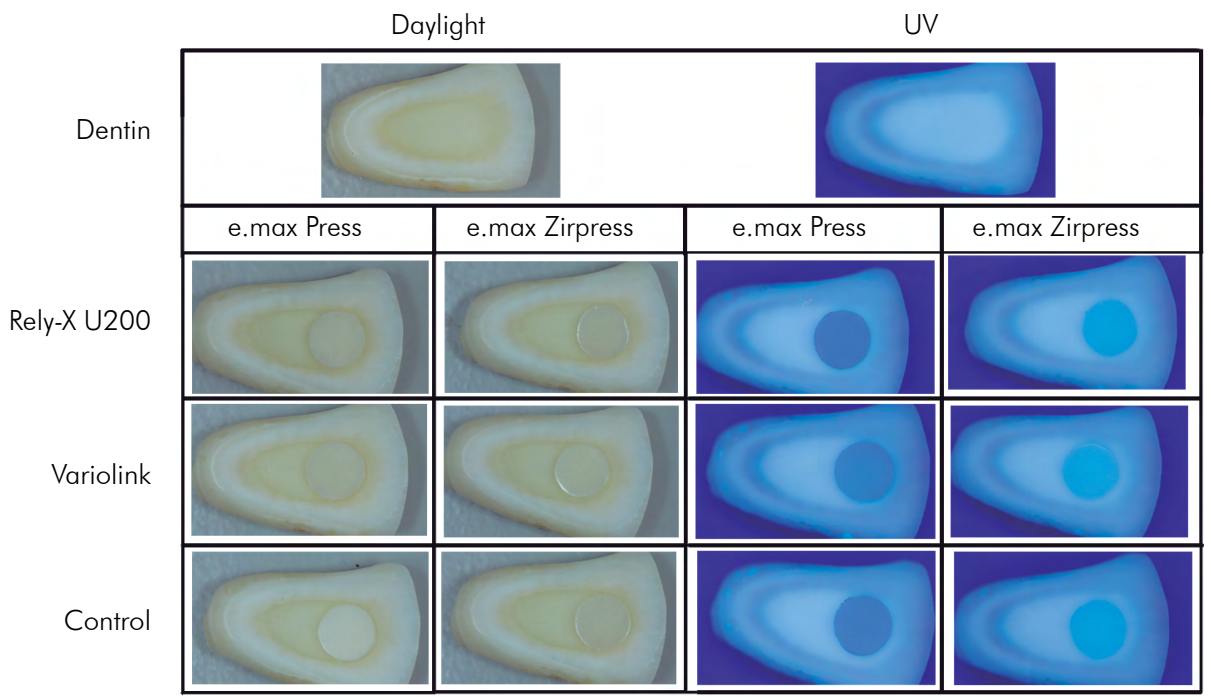

Figure 3. Images of the teeth, flattened on dentin, and the $1.0 \mathrm{~mm}$ veneers captured under daylight and UV-light.

Table 4. Comparison of fluorescence of the ceramics under daylight and UV light, without resin cements on enamel and dentin substrate.

\begin{tabular}{lcccc}
\hline \multirow{2}{*}{ Variable } & \multicolumn{3}{c}{ e.max Press } & \multicolumn{2}{c}{ e.max Zirpress } \\
\cline { 2 - 5 } & Daylight & UV & Daylight & UV \\
Bovine enamel & $0.95 \pm 0.03 a$ & $0.85 \pm 0.01 \mathrm{~b}$ & $0.95 \pm 0.01 \mathrm{a}$ & $0.98 \pm 0.01 \mathrm{~b}$ \\
Bovine dentin & $1.03 \pm 0.02 \mathrm{a}$ & $0.77 \pm 0.03 \mathrm{~b}$ & $0.97 \pm 0.01 \mathrm{a}$ & $0.86 \pm 0.00 \mathrm{~b}$ \\
\hline
\end{tabular}

Different letters in the lines indicate statistically significant results ( 1 -way ANOVA, Bonferroni, $p<0.05$ ).

\section{Discussion}

This study analyzed the influence of resin cements and ceramics with different thicknesses on the fluorescence intensity levels of dental laminate veneers using bovine enamel and bovine dentin substrates. The null hypothesis proposed was rejected given that there were statistical differences exhibited among the results.

The light-cured resin cement Variolink II presented a greater fluorescence level of ceramic veneers on enamel under UV illumination. The type of ceramic also presented a significant difference in fluorescence for all the dentin substrate veneer groups under each UV and daylight illumination. However, that was not the case for groups cemented with Variolink II.

Dental substrates are known for interfering with the esthetics of restoration veneers due to their reduced thickness ${ }_{1}^{16}$ especially at the gingival margin or finish line. The thickness of laminate veneers is, on average, $0.7 \mathrm{~mm} .{ }^{11}$ However, thickness measurements may vary depending on the presenting clinical variables including the amount of tooth structure removed during preparation.

This study employed a quantitative fluorescence image analysis process. Most fluorescence studies are conducted in vitro ${ }^{2,8,10}$ because they require direct UV-light emission. The natural tooth emits a fluorescence intensity at $\sim 450 \mathrm{~nm}$ with $U V$ excitation at $\sim 365 \mathrm{~nm} .{ }^{5}$ Emitting UV light directly into the oral cavity may possibly be harmful to soft tissues. As a result, protective gear against radiation is necessary to prevent damages. ${ }^{28} \mathrm{~A}$ recent study about ceramic's fluorescence used similar method this research with fluorescence measurement through pictures made inside the machine when UV-light ray was emitted directly onto the samples and then pictures were analyses for another software. ${ }^{29}$ Spectrometer was used to determine the significance of tooth fluorescence in natural sunlight on perceived tooth color. The color coordinates of samples were measured by the spectrometer in a lightbox with unfiltered 
and filtered sunlight and combined ultraviolet and visible spectrum and visible spectrum exclusively. ${ }^{12}$ Photography made with different combinations of incident light wavelengths and filters, and analyzed by histogram data from Adobe Photoshop can adjunct in forensic identification and recognize tooth restorations. ${ }^{30}$

Luminophores are inorganic oxides of rare earth minerals such as cerium, europium, terbium, ytterbium, dysprosium, and samarium. ${ }^{31}$ These minerals generate fluorescence when mixed together. ${ }^{14}$ Moreover, the fluorescence of the materials from the groups III, IV and V of the periodic classification (periodic table or periodical classification of elements) is very similar to natural tooth's fluorescence. ${ }^{5}$

In this study, two types of ceramic were used: IPS e.max Press, a lithium disilicate glass-ceramic (group I), and IPS e.max Zirpress, a fluorapatite glass-ceramic (group IV). Zirpress exhibited higher fluorescence with values closer to the natural tooth for both substrates, cements and control groups (no cement). Scientific documentation reports that e.max Press lithium disilicate crystals are 3-6 $\mu \mathrm{m}$ long, and that e.max ZirPress nano-scale, fluorapatite crystals are 2-5 $\mu \mathrm{m}$ long. ${ }^{26}$ This different microstructure aspect affects the absorption and scattering of light relative to fluorescence.

Fluorescence is less pronounced under the less stimulating daylight wavelengths but has a bigger impact in low lighting conditions when teeth and restorations exhibit different fluorescence. ${ }^{32}$ The exception was e.max Zirpress ceramic on the enamel substrate, both with and without resin cement. Since fluorescence level should only be stimulated under UV illumination, this study's examination process declared that a "fluorescence intensity" equaling 1 indicated that there was no difference between the fluorescence of the restoration and the tooth substrate.

Following this parameter establishment, the e.max Zirpress ceramic on the enamel substrate presented an acceptable fluorescence level under UV light, closer to natural dentition. Considering the dentin substrate, both types of ceramic presented low fluorescence levels under the UV light. This may be because dentin is more fluorescent than enamel and the restorations may require thicker veneers $(1 \mathrm{~mm})$.
The cement effect can increase or decrease the fluorescence of a restoration. In this study, the light-cured resin cement Variolink II altered the fluorescence level of the restoration when the e.max Press ceramic on the enamel substrate was placed under the UV illuminant. This alteration may be a result of Variolink II's composition, which includes ytterbium trifluoride, a compound that provides fluorescence. ${ }^{31}$ Given that the e.max Press ceramic exhibited less quantifiable fluorescence, the change may have been caused by the resin cement. The self-adhesive cement Rely X U200 (Table 1) reports no luminophores in its composition. That may possibly explain why the same fluorescence level was observed for the self-adhesive cement when compared to control groups (without resin cement, Tables 2 and 3). Within the context of this study, IPS e.max Zirpress exhibited greater fluorescence than the e.max Press. They have different microstructures, crystal structure, diffraction, and compositions. The light-cured resin cement (Variolink II) in combination with IPS e.max Press, exhibited a greater influence on the ceramic's fluorescence intensity. For almost all groups, daylight illumination had less impact on the ceramic's fluorescence intensity than the UV illuminant, except in the case of e.max Zirpress ceramic on the enamel substrate, both with and without resin cement.

Quantitative fluorescence image analysis made this particular research possible considering cost and software availability in contrast to the expensive, limited availability of highly specialized instrumentation used heretofore. Image analysis is, at the least, semi-quantitative and has been evolving in sophistication since the 1960s. It is widely used in a spectrum of medical diagnostics. Applicable software for image processing, such as the freely available NIH ImageJ, avail research contributions for such endeavors to many. Fluorescence of dental prostheses it a vital aspect for patient's appearance, that, in turn, is a significant health contribution, the reason for healthier dentition and greater smiles. Future studies should evaluate the influence of other ceramics on fluorescence, correlating material optical properties with the fluorescence findings. 


\section{Conclusion}

It was concluded that the type of ceramic is a significant factor for fluorescence. In addition, the IPS e.max Zirpress showed higher fluorescence than the e.max Press. The light-cured resin cement (Variolink
II), when combined with the IPS e.max Press, had a higher influence on the ceramic's fluorescence intensity. For almost all the groups, the daylight source had less impact on the ceramic's fluorescence intensity than the UV light source, except for the e.max Zirpress ceramic on enamel substrate, with and without resin cement.

\section{References}

1. Fondriest J. Shade matching in restorative dentistry: the science and strategies. Int J Periodontics Restorative Dent. 2003 Oct;23(5):467-79. https://doi.org/10.1016/i.prosdent.2004.03.015

2. Silva T, Oliveira H, Severino D, Balducci I, Huhtala M, Gonçalves S. Direct spectrometry: a new alternative for measuring the fluorescence of composite resins and dental tissues. Oper Dent. 2014 Jul-Aug;39(4):407-15. https://doi.org/10.2341/12-464-L

3. McLaren EA. Luminescent veneers. J Esthet Dent. 1997;9(1):3-12. https://doi.org/10.1111/j.1708-8240.1997.tb00909.x

4. Berns RS, Billmeyer FW, Saltzman M, Billmeyer FW. Billmeyer and Saltzman's principles of color technology. 3rd ed. New York: Wiley; 2000.

5. Panzeri H, Fernandes LT, Minelli CJ. Spectral fluorescence of direct anterior restorative materials. Aust Dent J. 1977 Dec;22(6):458-61. https://doi.org/10.1111/j.1834-7819.1977.tb05151.x

6. Tani K, Watari F, Uo M, Morita M. Discrimination between composite resin and teeth using fluorescence properties. Dent Mater J. 2003 Dec;22(4):569-80. https://doi.org/10.4012/dmi.22.569

7. Meller C, Klein C. Fluorescence properties of commercial composite resin restorative materials in dentistry. Dent Mater J. 2012;31(6):916-23. https://doi.org/10.4012/dmi.2012-079

8. Kim BR, Kang SM, Kim GM, Kim BI. Differences in the intensity of light-induced fluorescence emitted by resin composites. Photodiagn Photodyn Ther. 2016 Mar;13:114-9. https://doi.org/10.1016/i.pdpdt.2016.01.005

9. Uo M, Okamoto M, Watari F, Tani K, Morita M, Shintani A. Rare earth oxide-containing fluorescent glass filler for composite resin. Dent Mater J. 2005 Mar;24(1):49-52. https://doi.org/10.4012/dmi.24.49

10. Ecker GA, Moser JB, Wozniak WT, Brinsden GI. Effect of repeated firing on fluorescence of porcelain-fused-to-metal porcelains. J Prosthet Dent. 1985 Aug;54(2):207-14. https://doi.org/10.1016/0022-3913(85)90290-2

11. Alqahtani MQ, Aljurais RM, Alshaafi MM. The effects of different shades of resin luting cement on the color of ceramic veneers. Dent Mater J. 2012;31(3):354-61. https://doi.org/10.4012/dmi.2011-268

12. Hein S, Ten Bosch JJ. The effect of ultraviolet induced fluorescence on visually perceived tooth color under normal light conditions. Dent Mater. 2018 May;34(5):819-23. https://doi.org/10.1016/i.dental.2018.02.007

13. Rüttermann S, Ritter J, Raab WH, Bayer R, Janda R. Laser-induced fluorescence to discriminate between a dental composite resin and tooth. Dent Mater. 2007 Nov;23(11):1390-6. https://doi.org/10.1016/i.dental.2006.11.027

14. Foreman PC. The excitation and emission spectra of fluorescent components of human dentine. Arch Oral Biol. 1980;25(10):641-7. https://doi.org/10.1016/0003-9969(80)90094-1

15. Radz GM. Minimum thickness anterior porcelain restorations. Dent Clin North Am. 2011 Apr;55(2):353-70. https://doi.org/10.1016/i.cden.2011.01.006

16. Stevenson B, Ibbetson R. The effect of the substructure on the colour of samples/restorations veneered with ceramic: a literature review. J Dent. 2010 May;38(5):361-8. https://doi.org/10.1016/i.jdent.2010.01.009

17. Dozić A, Kleverlaan CJ, Meegdes M, Zel J, Feilzer AJ. The influence of porcelain layer thickness on the final shade of ceramic restorations. J Prosthet Dent. 2003 Dec;90(6):563-70. https://doi.org/10.1016/S0022-3913(03)00517-1

18. Bahannan SA, Awad MA. Effect of porcelain shade and application time on shade reproduction. J Prosthodont. 2018 Mar;27(3):227-31. https://doi.org/10.1111/jopr.12498

19. TurgutS, Bagis B. Colour stability of laminate veneers: an in vitro study. J Dent. 2011 Dec;39(3 Suppl 3):e57-64. https://doi.org/10.1016/i.jdent.2011.11.006

20. Wang F, Yu T, Chen J. Biaxial flexural strength and translucent characteristics of dental lithium disilicate glass ceramics with different translucencies. J Prosthodont Res. 2019 May;11:S1883-1958(19)30256-7. https://doi.org/10.1016/i.jpor.2019.04.007

21. Harada K, Raigrodski AJ, Chung KH, Flinn BD, Dogan S, Mancl LA. A comparative evaluation of the translucency of zirconias and lithium disilicate for monolithic restorations. J Prosthet Dent. 2016 Aug;116(2):257-63. https://doi.org/10.1016/i.prosdent.2015.11.019

22. Lin WS, Ercoli C, Feng C, Morton D. The effect of core material, veneering porcelain, and fabrication technique on the biaxial flexural strength and weibull analysis of selected dental ceramics. J Prosthodont. 2012 Jul;21(5):353-62. https://doi.org/10.1111/j.1532-849X.2012.00845.x 
Quantitative image of fluorescence of ceramic and resin-cement veneers

23. Morita RK, Hayashida MF, Pupo YM, Berger G, Reggiani RD, Betiol EA. Minimally invasive laminate venners: clinical aspects in treatment planing and cementation procedures. Case Rep Dent. 2016;2016:1839793. https://doi.org/10.1155/2016/1839793

24. Shafiei F, Memarpour M, Jowkar Z. Marginal sealing of a porcelain laminate veneer luted with three different resin cements on fluorosed teeth. Int J Esthet Dent. 2017;12(1):60-71.

25. Takahashi MK, Vieira S, Rached RN, Almeida JB, Aguiar M, Souza EM. Fluorescence intensity of resin composites and dental tissues before and after accelerated aging: a comparative study. Oper Dent. 2008 Mar-Apr;33(2):189-95. https://doi.org/10.2341/07-74

26. Ivoclar Vivadent. IPS e.max ${ }^{\circledR}$ press: instruções de uso. Shaan: Ivoclar Vivadent AG; 2019.

27. Sant'Anna Aguiar Dos Reis R, Casemiro LA, Carlino GV, Lins EC, Kurachi C, Bagnato VS, et al. Evaluation of fluorescence of dental composites using contrast ratios to adjacent tooth structure: a pilot study. J Esthet Restor Dent. 2007;19(4):199-206. https://doi.org/10.1111/j.1708-8240.2007.00100.x

28. Peplinski DR, Wozniak WT, Moser JB. Spectral studies of new luminophors for dental porcelain. J Dent Res. 1980 Sep;59(9):1501-6. https://doi.org/10.1177/00220345800590090801

29. Rafael CF, Güth JF, Kauling AE, Cesar PF, Volpato CA, Liebermann A. Impact of background on color, transmittance, and fluorescence of leucite based ceramics. Dent Mater J. 2017 Jul;36(4):394-401. https://doi.org/10.4012/dmj.2016-322

30. Kiran R, Walsh LJ, Forrest A, Tennant M, Chapman J. Forensic applications: fluorescence properties of tooth-coloured restorative materials using a fluorescence DSLR camera. Forensic Sci Int. 2017 Apr;273:20-8. https://doi.org/10.1016/i.forsciint.2017.01.022

31. Lu H, Lee YK, Villalta P, Powers JM, Garcia-Godoy F. Influence of the amount of UV component in daylight simulator on the color of dental composite resins. J Prosthet Dent. 2006 Nov;96(5):322-7. https://doi.org/10.1016/i.prosdent.2006.08.007

32. Monsénégo G. Contribution a l'etude de la fluorescence de la porcelaine dentaire (These). Paris: Universitv of Paris, 1991. 